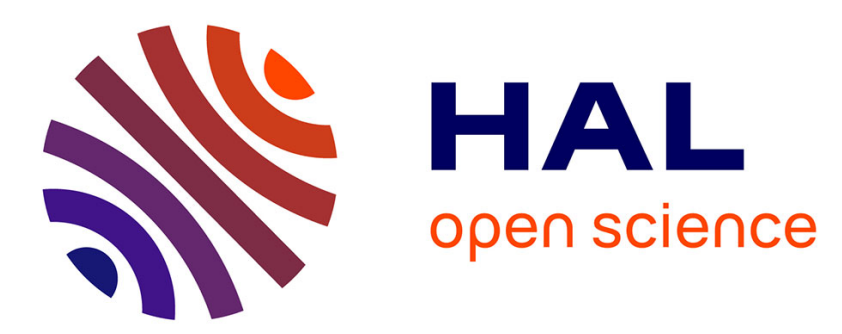

\title{
Effects of carotid baroreceptor stimulation on retinal arteriole remodeling evaluated with adaptive optics camera in resistant hypertensive patients
}

\author{
A. Gallo, D. Rosenbaum, C. Kanagasabapathy, X. Girerd
}

\section{To cite this version:}

A. Gallo, D. Rosenbaum, C. Kanagasabapathy, X. Girerd. Effects of carotid baroreceptor stimulation on retinal arteriole remodeling evaluated with adaptive optics camera in resistant hypertensive patients. Annales de Cardiologie et d'Angéiologie, 2017, 10.1016/j.ancard.2017.04.007 . hal-01540290

\section{HAL Id: hal-01540290 \\ https: / hal.sorbonne-universite.fr/hal-01540290}

Submitted on 16 Jun 2017

HAL is a multi-disciplinary open access archive for the deposit and dissemination of scientific research documents, whether they are published or not. The documents may come from teaching and research institutions in France or abroad, or from public or private research centers.
L'archive ouverte pluridisciplinaire HAL, est destinée au dépôt et à la diffusion de documents scientifiques de niveau recherche, publiés ou non, émanant des établissements d'enseignement et de recherche français ou étrangers, des laboratoires publics ou privés. 
Title

Effects of carotid baroreceptor stimulation on retinal arteriole remodeling evaluated with adaptive optics camera in resistant hypertensive patients.

Effets de la stimulation du barorécepteur carotidien sur le remodelage artériolaire rétinien évalué par l'Optique Adaptative chez l'hypertendu résistant.

- A. Gallo, $\underline{a}$, , ,

- D. Rosenbaum ${ }^{\mathrm{a}, \mathrm{b}}, \underline{\mathrm{c}}$,

- C. Kanagasabapathy

- $\underline{\text { X. Girerd }}{ }^{a}$

\begin{abstract}
Background and Aim. Baroreceptor activation therapy (BAT) leads to a decrease in blood pressure (BP) in patients affected by resistant hypertension $(\mathrm{RH})$ by reducing sympathetic outflow.

This study aimed at evaluating the effects of BAT on RH patients' retinal arteriolar microvasculature, a territory devoid of adrenergic innervation.

Patients and Methods. Five patients defined as affected by RH after excluding secondary causes of hypertension and based on number of anti-hypertensive treatments, underwent the implantation of Barostim $^{\mathrm{TM}} n e o^{\mathrm{TM}}$. Systolic Blood Pressure (SBP) and Diastolic Blood Pressure (DBP) were assessed by office and 24-hours ambulatory BP monitoring (ABPM). Adaptive Optics Camera RTX1@ (ImagineEye, Orsay, France) was used to measure wall thickness (WT), internal diameter (ID), wall cross sectional area (WCSA) and wall-to-lumen ratio (WLR). A cohort of 21 notcontrolled hypertensive patients matched for age, gender and follow-up time, undergoing standardantihypertensive therapy changes, was selected as a control group. SBP and DBP were assessed by office and home BP monitoring (HBPM). Evaluations were performed at baseline and after 6 months mean follow-up.
\end{abstract}

Results. Office SBP decreased by $9.7 \pm 12.3 \%$ and $29.7 \pm 12.4 \%$ in standard-therapy and BAT group respectively, while office DBP decreased by $7.6 \pm 17.4 \%$ and $14.8 \pm 15.7 \%$. Concerning ABPM/HBPM, a mean reduction of both SBP and DBP of $7.9 \pm 11 \%$ was observed for the standardtherapy while a reduction of $15.8 \pm 10.5 \%$ and $15.8 \% \pm 5.3 \%$ was observed for SBP and DBP respectively in BAT group. While in the standard therapy group a significant reduction in WLR ($5.9 \%)$ due to both ID increase $(+2.3 \%)$ and WT reduction $(-5.7 \%)$ was observed, without changes in WCSA $(-0.3 \%)$, RH patients had a significant reduction in WCSA $(-12.1 \%)$, due to a trend in both WT and ID reduction (-6.5\% and $-1.7 \%$ respectively), without significant changes in WLR ($2 \%$ ) 
Conclusion. While a reverse eutrophic remodeling was observed in patients undergoing a standardantihypertensive treatment, hypotrophic changes were found in RH patients undergoing BAT.

Despite the lack of adrenergic receptors on retinal vessels, chronic baroreflex stimulation may exert an effect on retinal microvasculature in RH patients by more systemic than local mechanisms.

\section{Key words}

adaptive optics camera, resistant hypertension, retina, arteriolar remodeling, microcirculation

\section{Résumé}

Contexte et But de l'étude. La thérapie de stimulation des barorécepteurs (TSB) conduit à une diminution de la pression artérielle chez l'hypertendu résistant par une réduction de la décharge du système sympathique. Cette étude a comme objectif l'évaluation des effets de la TSB sur la microcirculation rétinienne, un territoire dépourvu d'innervation adrénergique, dans l'hypertension résistante (HR).

Patients et méthode. Cinq patients atteints d'une HR, définie sur la base du nombre de médicaments, ayant exclus toute cause secondaire d'hypertension, ont eu l'implantation du Barostim $^{\mathrm{TM}}$ neo ${ }^{\mathrm{TM}}$. La Pression Systolique (PAS) et Diastolique (PAD) ont été mesurées en consultation et par MAPA. La caméra d'Optique Adaptative RTX1® (ImagineEye, Orsay, France) a été utilisée pour calculer l'épaisseur de paroi (WT), la lumière (ID), l'aire cross-sectionnelle (WCSA) et le rapport paroi-lumière (WLR). Vingt-et-un hypertendus non contrôlés appariés pour âge, sexe et temps de suivi ont été recrutés en tant que témoins, ayant une adaptation du traitement antihypertenseur. La PAS et PAD ont été mesurées en consultation et au domicile. Les évaluations tensionnelles et rétiniennes ont été réalisées avant le début de la TSB où de l'adaptation du traitement, et après 6 mois de suivi.

Résultats. Après 6 mois on a observé une diminution moyenne de PAS en consultation de $29.7 \pm 12.4 \%$ et $9.7 \pm 12.3 \%$ chez les patients TSB et les témoins respectivement et une diminution moyenne de PAD de $14.8 \pm 15.7 \%$ et $7.6 \pm 17.4 \%$ respectivement. Une diminution moyenne de $15.8 \pm 10.5 \%$ pour la PAS et $15.8 \% \pm 5.3 \%$ pour la PAD a été observée pour les MAPA chez les patients TSB et chez les témoins il y a eu une diminution de PAS et PAD de $7.9 \pm 11 \%$ pour les automesures. Les témoins ayant eu une adaptation standardisée du traitement antihypertenseur ont montré une baisse significative du WLR (-5.9\%) en rapport à une augmentation de 1'ID (+2.3\%) et à une réduction du WT (-5.7\%), sans modification du WCSA (-0.3\%). Par contre, les patients avec HR ont montré une diminution significative du WCSA (-12.1) liée à une tendance à la baisse du WT et du ID (-6.5\% et $-1.7 \%$, respectivement), sans modification du WLR (-2\%).

Conclusion. Un remodelage eutrophique inverse est observé chez l'hypertendu non contrôlé ayant une adaptation classique du traitement antihypertenseur, alors que l'on a un pattern de modification hypotrophique chez l'hypertendu résistant. Malgré l'absence de récepteurs adrénergique sur les vaisseaux rétiniens, une stimulation chronique du baroreflex chez l'hypertendu résistant a un effet sur a microcirculation rétinienne dont les mécanismes systémiques plutôt que locaux.

\section{Mot clés}


Optique adaptative, microcirculation, hypertension résistante, rétine, remodelage artériolaire

\section{Introduction}

Novel strategies for a better management of Resistant Hypertension (RH) are being sought. Apart from pharmacologic treatment, which by definition should already be at adequate dose, novel invasive therapeutic strategies have been introduced lately, among which the Barorefex Activation Therapy (BAT).

$\mathrm{RH}$ is characterized by an increased sympathetic activity that regulates vascular smooth muscle tone by increased circulating levels of noradrenaline[1]. Simultaneously, a decrease in parasympathetic activity is found. By stimulating the afferent nerve fibers of carotid sinus baroreceptors, BAT determines a central reduction in sympathetic outflow with an increased parasympathetic activity[2].

Apart from the renovated interest in Sympathetic Nervous System (SNS) activity in arterial hypertension, solid evidences exist about micro- and macrovascular remodeling taking place in arterial hypertension. Effects on large vessels like an increase in wall thickness and a reduction in lumen diameter, as well as an increased stiffness have been shown early in hypertension, independently from aging effects[3].

Retinal microvasculature is the only microvascular territory directly approachable in a non-invasive fashion. Retinal arteriolar remodeling has been found to have the same characteristics of large vessel remodeling, with an increase in wall-to-lumen ratio (WLR) observed in hypertensive patients, representing an inward eutrophic remodeling. A reverse remodeling process has also been shown after the start of standard antihypertensive therapy in newly diagnosed or non-controlled non-resistant hypertensive patients[4,5]. As retinal vessels are typically devoid of adrenergic receptors and are not directly influenced by SNS, no direct effects of acute BAT-induced BP changes are expected on retinal microcirculation. Long-term BAT effects on retinal arterioles in $\mathrm{RH}$ have never been analyzed.

Hence, the main objectives of our study were $1 /$ to study the effects of BAT on retinal microcirculation in patients with $\mathrm{RH}$ and 2/ to compare them with a group of not-controlled hypertensive patients undergoing an adaptation of antihypertensive therapy.

\section{Materials and Methods}

Study population 
Between June 2015 and December 2015 in the Cardiovascular Prevention Unit of Pitié-Salpêtrière University Hospital, Paris, we consecutively enrolled 5 patients affected by RH (as defined by 2013 ESC guidelines), aged from 20 to 60 years old, without contraindication for the implantation of the device, with no recent history of cardiovascular disease.

In the same time period we selected 21 not-controlled not-RH patients without recent history of cardiovascular disease. They were matched for age, gender and follow-up time.

Exclusion criteria were refusal to give consent and technical obstacles to AOC assessment.

The study was carried out according to the principles outlined in the Declaration of Helsinki. Approval of the local Ethics Committee was obtained and informed consent was given by all participants.

\section{BP Measurements}

Office brachial BP was assessed in standard conditions in seated position during the outpatient visit using an oscillometric device simultaneously to AOC assessment.

In RH patients, BP was confirmed with 24-h ABPM using an oscillometric device (Spacelabs) applied to the non-dominant arm.

Home BP measurements (HBPM) were performed in standard-therapy group. HBPM were taken using validated electronic arm devices. Values were recorded as the mean systolic BP and diastolic $\mathrm{BP}$ of three consecutive measurements made every 2 minutes in the morning and in the evening, after 5 minutes in sitting position, for three consecutive days.

Both ABPM and HBPM were obtained at baseline and follow-up.

\section{Therapeutic device}

The stimulation system used was the Barostim ${ }^{\mathrm{TM}}$ neo $o^{\mathrm{TM}}$ (CVRx., Minneapolis, MN, USA). A detailed description of the device has been already provided[6]. All 5 patients had been implanted on the right side. After successful implantation the intensity, frequency and pulse duration were progressively adapted to patients' response in terms of BP control and local symptoms during the first month, being the pulse generator programmable by radio-frequency control through an external software. Stimulation was constant during the whole circadian cycle.

\section{Small arteries: wall to lumen ratio estimation by adaptive optics}

Adaptive Optics Camera (AOC) fundus images were obtained using a commercially available flood-illumination AOC retinal camera ( $\mathrm{rtx} 1^{\mathrm{TM}}$; Imagine Eyes, Orsay, France).The detailed procedure of images acquisition and treatment has been previously reported[7].

Retinal imaging was performed by an operator blinded to clinical data at the Cardiovascular Prevention Unit. The ratio of total parietal thickness over the lumen diameter averaged along $250 \mu \mathrm{m}$ length defined the WLR. Wall thickness (WT) was defined as WT $=($ Outer Diameter (OD) - Internal Diameter (ID)) and total wall cross sectional area (WCSA) as $\pi *\left((\mathrm{OD} / 2)^{2}-(\mathrm{ID} / 2)^{2}\right)$. Intra observer reproducibility of microvasculature anatomical indices were already published $[7,8]$.

\section{Definition of Resistant Hypertension}

Patients were considered as affected by RH if their office and home BP had been respectively $>140 / 90$ and $>135 / 85 \mathrm{mmHg}$ for at least six months despite triple anti-hypertensive therapy at adequate dose, including a diuretic. 


\section{Patients follow-up}

Baseline evaluation was made during the outpatients visit before the implantation of the device for BAT group and at the first consulting for standard-therapy group. Antihypertensive therapy for the standard-therapy group was chosen according to recent guidelines [9]. Patients from both treatment groups were re-evaluated at one and six months after either device implantation or antihypertensive therapeutic adaptation.

\section{Statistical analysis}

All continuous variables are expressed as mean (SD), unless otherwise stated. Differences between groups were evaluated by variance analysis and Student's t test. Distribution of categorical variables between groups was evaluated using the $\chi^{2}$ test. Before-and-after observations were made by paired t-test. Normality of continuous variables distribution was tested using Kolmogorov-Smirnov test. For parametric tests non parametric variables were log-transformed. Analyses were performed using SPSS v23 (Chicago, Illinois). A probability value $<0.05$ was considered statistically significant.

\section{Results}

Key baseline characteristics were comparable in the two groups (Table 1). Interestingly, a trend toward a higher ID and WCSA was observed in RH patients, although not statistically significant. As compared to standard-therapy group, BAT group had a higher number of medications and higher office and home SBP, as expected. The median (IQR) follow-up time was 182 (122-196) days for BAT group and 192 (74-417) days for standard-therapy group ( $\mathrm{p}=0.8)$. Interestingly, patient in the BAT group had had a failed attempt of renal denervation. Both therapeutic interventions were efficient, as shown in Table 2: office SBP decreased by $9.7 \pm 12.3 \%$ and $29.7 \pm 12.4 \%$ in standardtherapy and BAT group respectively, while office DBP decreased by $7.6 \pm 17.4 \%$ and $14.8 \pm 15.7 \%$. Concerning ABPM/HBPM, a mean reduction of $7.9 \pm 11 \%$ for both SBP and DBP was observed for the standard-therapy while a reduction of $15.8 \pm 10.5 \%$ and $15.8 \% \pm 5.3 \%$ was observed for SBP and DBP respectively in BAT group. As shown in Figure 1, while in the standard therapy group a significant reduction in WLR $(-5.9 \%)$ due to both ID increase $(+2.3 \%)$ and WT reduction $(-5.7 \%)$ was observed, without changes in WCSA $(-0.3 \%)$, RH patients had a significant reduction in WCSA $(-12.1 \%)$, due to a trend in both WT and ID reduction (-6.5\% and $-1.7 \%$ respectively), without significant changes in WLR $(-2 \%)$. Differences in retinal remodeling indexes changes were not statistically significant between the two treatment groups.

\section{Discussion}

In this study we analyzed retinal microcirculatory adaptation to BP changes in patients with RH. While a reverse eutrophic remodeling was observed in patients undergoing a standardantihypertensive treatment adaptation, hypotrophic changes were found in $\mathrm{RH}$ patients undergoing BAT.

Findings in the standard therapy group are in line previously published results. In a cohort of 45 hypertensive patients undergoing antihypertensive treatment improvement, we found a significant reduction in WLR $(-6 \%)$ together with an increase of ID $(+4.4 \%)$, thus confirming the reverse eutrophic remodeling after BP control in hypertensive patients [4]. 
A difference is the arteriolar reverse remodeling observed in the two groups could be related to the different observed BP drop independently from BAT therapy. This mechanism should be therefore related to a different baseline condition (e.g. hypertrophic remodeling in $\mathrm{RH}$, as observed in secondary hypertension), but this was not the case of our cohort.

In RH patients we only observed a reduction in WCSA, without changes in WLR despite a reduction trend in both WT and ID. To our knowledge, this is the first time that a hypotrophic pattern is observed in vivo on retinal small arteries. To explain this observation, a first assumption could be that these patients may have a damaged myogenic tone response as reflected by the fact that they are not responders to vasoactive antihypertensive drugs[10-12]. A typical myogenic tone response was observed in the standard therapy group after the introduction of calcium-channel blockers, beta-blockers or ACE-Inhibitors/Angiotensin receptor blockers where changes in WLR were due to a combined vasodilatation and wall thinning. Another reason may be that while eutrophic remodeling is the earliest event taking place in the crosstalk between micro and macrocirculation, anticipating the development of prognostically important features (such as left ventricular hypertrophy), a decrease in SNS activity could be responsible of the hypotrophic pattern changes. Renal denervation, as well as BAT, have already been shown to determine a regression of left ventricular hypertrophy, mainly due to myocyte hypertrophy reversal[13,14]. Finally, the role of baroreflex stimulation may explain the different long term retinal response in our cohorts. As recently hypothesized [15], common anti-hypertensive drugs may exert an effect of decreasing baroreceptors stimuli, which may determine a compensatory activation of the SNS. In the long-term this may lead to an inefficient anti-hypertensive effect leading to RH. BAT would counteract this compensatory effect, determining the significant decrease in BP that we as others observed [16].

Contrary to choroidal vasculature, retinal microcirculation is characterized by the absence of any sympathetic stimuli influence [17]. While baroreflex activation decreases peripheral resistance in sympathetic-stimuli-responder territories, it has no effect on retinal vascular resistance. An explanation for the long-term effect of BAT on retinal microvasculature is that chronic baroreflex stimulation may exert an effect on renal-controlled fluid balance. Interestingly, all 5 patients had undergone renal denervation therapy, without success. Behind the success of BAT compared to renal denervation there may be an insufficient natriuretic effect of renal nerve fibers, which may determine a redundant natriuretic response, mediated by an increase in atrial natriuretic peptide secretion, increased renal interstitial fluid pressure and reduced plasma protein concentration [15].

This is the first study to evaluate in vivo retinal microvascular long-term effects of baroreflex stimulation in RH, expressed by hypotrophic changes. The direct visualization of retinal microcirculation is a unique opportunity to examine body's microvasculature safely and noninvasively in vivo.

The main limitation of this study is that BAT group consisted of only 5 patients, which makes of this a pilot study without the possibility to draw conclusions. However, even with this small sample, we were able to observe a statistically significant hypotrophic effect of BAT on retinal microvasculature. Adaptive Optics represents a reliable methodology, characterized by small intraobserver variability and allows a high-definition study of arteriolar structure [18].

\section{Conclusion}


A hypotrophic pattern is observed in the retinal vasculature subjected to long-term BAT. Despite the lack of adrenergic receptors on retinal vessels, chronic baroreflex stimulation may exert an effect on retinal microvasculature in RH patients by more systemic than local mechanisms.

Acknowledgements: We thank Mme Caroline Kanagasabapathy for AOC images acquisition and analysis.

The authors report no conflict of interest.

\section{References}

1. Mäki-Petäjä KM, Barrett SML, Evans SV, Cheriyan J, McEniery CM, Wilkinson IB. The Role of the Autonomic Nervous System in the Regulation of Aortic Stiffness. Hypertension. 2016;68:1290-1297.

2. Heusser K, Tank J, Engeli S, et al. Carotid baroreceptor stimulation, sympathetic activity, baroreflex function, and blood pressure in hypertensive patients. Hypertension 2010;55:619 -26 .

3. Schiffrin EL. Vascular remodeling in hypertension: mechanisms and treatment. Hypertension. 2012 Feb;59(2):367-74.

4. Rosenbaum D, Mattina A, Koch E, Rossant F, Gallo A, Kachenoura N, et al. Effects of age, blood pressure and antihypertensive treatments on retinal arterioles remodeling assessed by adaptive optics. J Hypertens 2016 Jan; 34:1115-1122

5. De Ciuceis C, Salvetti M, Rossini C, Muiesan ML, Paini A, Duse S, et al. Effect of antihypertensive treatment on microvascular structure, central blood pressure and oxidative stress in patients with mild essential hypertension. J Hypertens. 2014 Mar;32(3):565-74.

6. Hoppe UC, Brandt MC, Wachter R, Beige J, Rump LC, Kroon AA, et al. Minimally invasive system for baroreflex activation therapy chronically lowers blood pressure with pacemaker-like safety profile: results from the Barostim neo trial. J Am Soc Hypertens 2012;6:270-276.

7. Koch E, Rosenbaum D, Brolly A, Sahel J-A, Chaumet-Riffaud P, Girerd X, et al. Morphometric analysis of small arteries in the human retina using adaptive optics imaging: relationship with blood pressure and focal vascular changes. J Hypertens. 2014 Apr;32(4):890-8.

8. Gallo A, Mattina A, Rosenbaum D, Koch E, Paques M, Girerd X. Retinal arteriolar remodeling evaluated with adaptive optics camera: Relationship with blood pressure levels. Ann Cardiol Angeiol (Paris). 2016 Jun;65(3):203-7.

9. Mancia G, Fagard R, Narkiewicz K, Redon J, Zanchetti A, Bohm M, et al. 2013 ESH/ESC Guidelines for the management of arterial hypertension: the Task Force for the management of arterial hypertension of the European Society of Hypertension (ESH) and of the European Society of Cardiology (ESC). J Hypertens. 2013 Jul;31(7):1281-357. 
10. Schiffrin EL, Park JB, Pu Q. Effect of crossing over hypertensive patients from a $\beta$-blocker to an angiotensin receptor antagonist on resistance artery structure and on endothelial function. J Hypertens.2002;20:71-78.

11. Ghiadoni L, Virdis A, Magagna A, Taddei S, Salvetti A. Effect of the angiotensin II type 1 receptor blocker candesartan on endothelial function in patients with essential hypertension. Hypertension. 2000;35:501-506.

12. Mulvany MJ, Baumbach GL, Aalkjaer C, Heagerty AM, Korsgaard N, Schiffrin EL, et al. Vascular remodeling. Hypertension. 1996;28:505-506.

13. Georgakopoulos D, Little WC, Abraham WT, Weaver FA, Zile MR. Chronic Baroreflex Activation: A Potential Therapeutic Approach to Heart Failure With Preserved Ejection Fraction. J Cardiac Fail 2010;1e12.

14. Mahfoud F, Urban D, Teller D, Linz D, Stawowy P, Hassel JH, et al. Effect of renal denervation on left ventricular mass and function in patients with resistant hypertension: data from a multicenter cardiovascular magnetic resonance imaging trial. Eur Heart $\mathbf{J}$ 2014;35:2224-231b.

15. Lohmeier TE, Iliescu R. The Baroreflex as a long-term controller of arterial pressure. Physiology (Bethesda).2015 Mar;30(2):148-158.

16. Scheffers IJM, Kroon AA, Schmidli J, Jordan J, Tordoir JJM, Mohaupt MG, et al.Novel Baroreflex Activation Therapy in Resistant Hypertension Results of a European MultiCenter Feasibility Study. J Am Coll Cardiol 2010;56:1254-8.

17. Kur J, Newman EA, Chan-Ling T. Cellular and physiological mechanisms underlying blood flow regulation in the retina choroid in health disease. Prog Retin Eye Res 2012 Sep;31(5):377-406.

18. Rosenbaum D, Koch E, Girerd X, Rossant F, Pâques M. [Imaging of retinal arteries with adaptative optics, feasibility and reproducibility]. Ann Cardiol Angeiol (Paris). 2013 Jun;62(3):184-8. 
Table 1. Characteristics of the patients at baseline

\begin{tabular}{lccc} 
& BAT & $\begin{array}{c}\text { Standard antihypertensive } \\
\text { therapy }\end{array}$ & p value \\
\hline \hline $\mathbf{n}$ & 5 & 21 & \\
\hline Age, $\mathbf{y}$ & $50.4 \pm 5.6$ & $55.4 \pm 9.9$ & $\mathrm{NS}$ \\
Gender, men (\%) & $3(60)$ & $13(61.9)$ & $\mathrm{NS}$ \\
\hline Current smoking (\%) & $1(20)$ & $4(19)$ & $\mathrm{NS}$ \\
Diabetes mellitus (\%) & 0 & $2(9.5)$ & $\mathrm{NS}$ \\
$\mathbf{N}^{\circ}$ Antihypertensive treatment & $4.6 \pm 0.5$ & $0.8 \pm 1.3$ & $<0.001$ \\
\hline Office SBP, mmHg & $193.0 \pm 29.5$ & $153.4 \pm 29.4$ & 0.012 \\
Office DBP, mmHg & $105.4 \pm 13.7$ & $89.2 \pm 17.0$ & $\mathrm{NS}$ \\
Home SBP, mmHg & $182.8 \pm 17.4$ & $144.2 \pm 13.9$ & $<0.001$ \\
Home DBP, mmHg & $105.5 \pm 12.7$ & $91.5 \pm 13.5$ & $\mathrm{NS}$ \\
\hline Wall-to-Lumen Ratio & $0.332 \pm 0.09$ & $0.347 \pm 0.09$ & $\mathrm{NS}$ \\
Internal Diameter, $\boldsymbol{\mu m}$ & $76.7 \pm 10.4$ & $72.76 \pm 9.9$ & $\mathrm{NS}$ \\
Wall Thickness, $\boldsymbol{\mu m}$ & $25.88 \pm 4.04$ & $24.58 \pm 4.6$ & $\mathrm{NS}$ \\
Wall Cross Sectional Area, $\boldsymbol{\mu m}^{\mathbf{2}}$ & $3744.76 \pm 530.4$ & $3284.56 \pm 698$ & $\mathrm{NS}$ \\
\hline \hline
\end{tabular}

BAT, Baroreflex Activation Therapy; SBP, Systolic Blood Pressure; DBP,Diastolic Blood Pressure

Table 2. Blood pressure changes in study population according to treatment groups, at baseline and follow-up

Baseline $\quad$ Follow-up p value

$\operatorname{BAT}(\mathbf{n}=5)$

\begin{tabular}{lccc}
\hline Office SBP $(\mathbf{m m H g})$ & $193.0 \pm 29.5$ & $137.8 \pm 43.3$ & 0.003 \\
Office DBP $(\mathbf{m m H g})$ & $105.4 \pm 13.7$ & $89.6 \pm 19.2$ & 0.09 \\
ABPM SBP $(\mathbf{m m H g})$ & $182.8 \pm 17.4$ & $153.5 \pm 20.6$ & 0.036 \\
ABPM DBP $(\mathbf{m m H g})$ & $105.5 \pm 12.7$ & $88.6 \pm 10.3$ & 0.003 \\
\hline
\end{tabular}

STANDAR THERAPY $(\mathrm{n}=21)$

\begin{tabular}{lccc}
\hline Office SBP $(\mathbf{m m H g})$ & $153.4 \pm 29.4$ & $136.2 \pm 19.8$ & 0.002 \\
Office DBP $(\mathbf{m m H g})$ & $89.2 \pm 17.0$ & $80.5 \pm 11.9$ & 0.024 \\
HBPM SBP $(\mathbf{m m H g})$ & $144.2 \pm 13.9$ & $133.2 \pm 13.6$ & 0.025 \\
HBPM DBP $(\mathbf{m m H g})$ & $91.5 \pm 13.5$ & $82.7 \pm 8.8$ & 0.026 \\
\hline \hline
\end{tabular}

BAT, Baroreflex Activation Therapy; SBP, Systolic Blood Pressure; DBP, Diastolic Blood Pressure; ABPM, 24- $h$ Ambuatory Blood Pressure Measurement; HBPM, Home Blood Pressure Measurement 
Figure 1. Retinal microvascular indexes changes in study population stratified by treatment group.

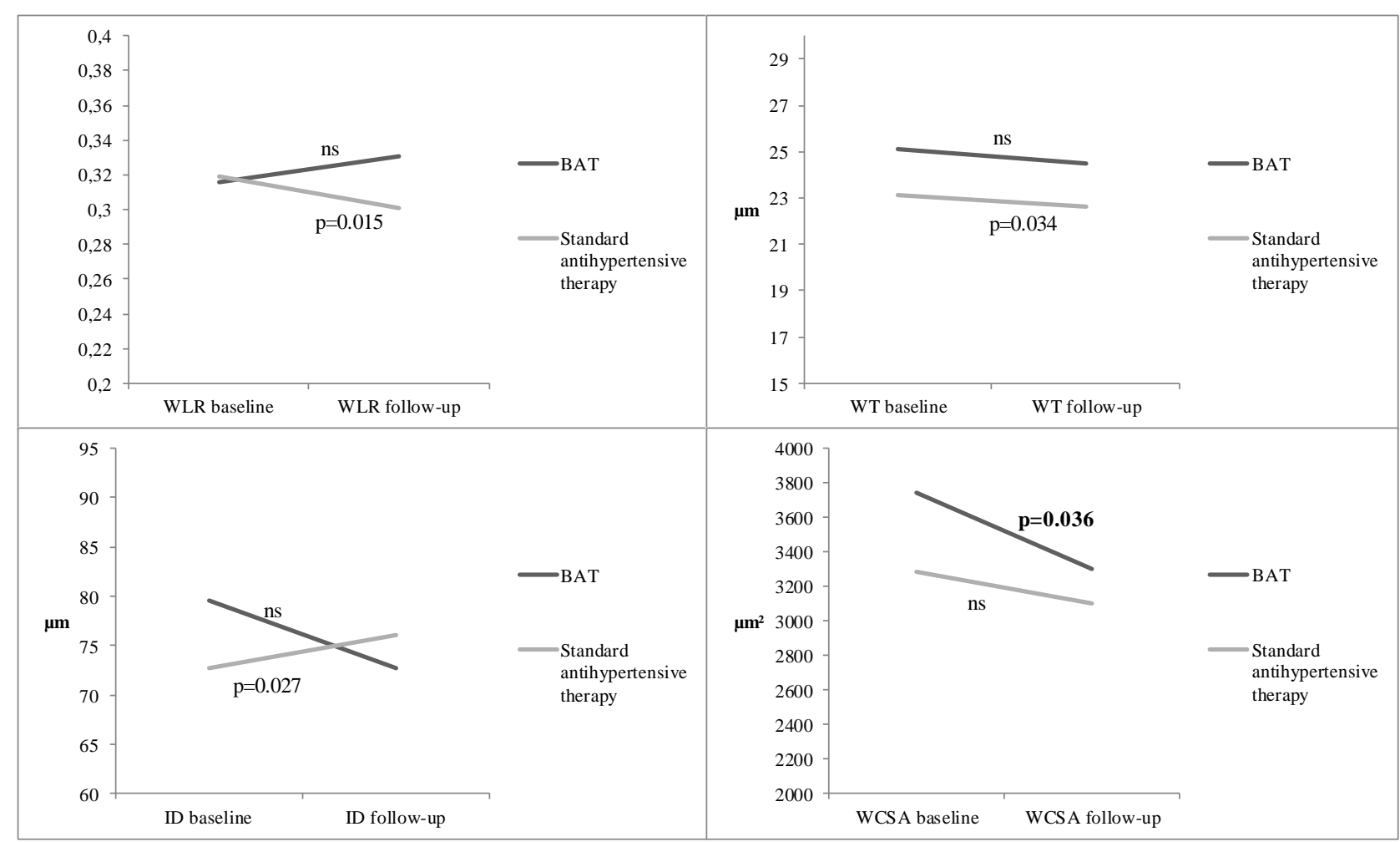

